\title{
Vehicle Drive Control Using Fuzzy Based PI Speed Controller
}

\author{
Dr. Subarna Shakya, Professor, \\ Department of Electronics and Computer Engineering, \\ Central Campus, Institute of Engineering, \\ Pulchowk, Tribhuvan University, \\ Pulchowk, Lalitpur Nepal. \\ Email: drss@ioe.edu.np.
}

\begin{abstract}
This paper proposes a fuzzy PI speed controller which is used in electric vehicle's drive control system insensitive to parameter change and disturbance, using fuzzy control theory. A permanent magnet synchronous motor (PMSM) is modelled mathematically in d-q reference frame. In this paper, a sliding model and fuzzy control theory are used to simulate the PMSM models using fuzzy control theory. Simulink software is used to analyze and simulate the simulation models which show that the proposed PI control based on fuzzy logic will have better anti-interference, better dynamic performance, and faster dynamic response speed when compared with the sliding motor control. Hence the proposed methodology is considered to be the ideal control method with a predefined vector control reference value for the electric vehicle's motor.
\end{abstract}

Keywords: Fuzzy Logic, PI speed controller, permanent magnet synchronous motor, electric vehicle

\section{Introduction}

Electric vehicle driving system has seen the various advantages of permanent magnet synchronous in the recent years which include satisfactory control characteristics, high power density and high efficiency [1]. This is because the riding comfort, safety and manoeuvrability of the vehicle is highly influenced by the control performance of the driver motor. Moreover, PMSM motors offer high rate of response to the changes in the environment and parameters, enabling an improved robustness of the drive motor. Over the years, there have been many research work performed by scholars who have studied and improved the speed vector control of the PMSM. In [2] Zheng and Pi proposed a digital hardware designed to use the PMSM with speed sensorless control along with Kalman filter to determine the rotor speed and rotor flux angle. This was then fed back to speed control loop and current control loop where PI controllers are used to process it further, resulting in a complex control system. $\mathrm{Ji}$ and $\mathrm{Li}$ in [3] used neural network back propagation to develop a space vector pulse width modulation control algorithm. The BP neural network was designed to modulate the triangular carrier modulation wave of SVPWM such that three-phase inverter control signal could be figured out. However the drawback with this method is that BPNN is considerably slow during operation. On the other hand, in [4] Xu and Lin proposed an integrated control method of speed and position depending on sliding mode which gave the answer for sliding mode variable structure control problem. However the drawback with 
this method is that it produced high frequency noise that influenced the controller's performer when the speed differential is obtained. Similarly Zhu et al., in [5] proposed a radial basis function NN that worked on online estimation system. This methodology executed improved performance of the motor system though the performance index function was more intricate. As observed by Yuan and Lin in [6], combining sliding mode control with fuzzy control will result in decrease of chattering problem, however the practicality of the issue is weak. The proposed work is based on fuzzy PI for PMSM vector control in electric vehicles. This method is modelled mathematically in d-q reference frame while a sliding model and fuzzy control theory are used to simulate the PMSM models using fuzzy control theory. Simulink software is used to analyze and simulate the simulation models which show waveforms of three phase current, torque and speed. The output of the simulation shows that when PMSM vector control is performed through fuzzy PI, it offers advantages like excellent robustness and high feasibility[11-13].

\section{Mathematical Modelling}

Mechanical Energy is obtained from electrical energy by conversion using PMSM as a part of the driving electric vehicle, resulting in a multivariable, nonlinear system [7]. For ease of calculation and simplification, let us consider PMSM to be a linear system such that motor parameters are unaffected by temperature, rotor damper winding, hysteresis loss and eddy current loss. Based on these assumptions, in the d-q reference frame, mathematical modelling of PMSM takes place. Let the stator voltage be represented by (1)

$$
\left\{\begin{array}{c}
u_{d}=R i_{d}+L_{s} \frac{d i_{d}}{d_{t}}-p_{n} w_{m} L_{s} i_{q} \\
u_{q}=R i_{q}+L_{s} \frac{d i_{q}}{d_{t}}-p_{n} w_{m} L_{s} i_{d}+p_{n} \omega_{m} \varphi_{f}
\end{array}\right.
$$

where $\omega_{m}$ represents the electric angular velocity, $p_{n}$ is the extreme logarithm, $L_{s}$ is the inductance of stator, $i_{d}$ and $i_{q}$ represent the current along $d$ and $q$ axis respectively, and the magnetic flux linkage is represented by $\varphi_{f}$.

Similarly, the torque of the electric motor can be represented by equation (2)

$$
T_{e}=\frac{3}{2} p_{n}\left[i_{q} \varphi_{f}+i_{d} i_{q}\left(L_{d}-L_{q}\right)\right]
$$

where $\mathrm{L}_{\mathrm{q}}$ and $\mathrm{L}_{\mathrm{d}}$ are the inductors $\mathrm{q}$ and $\mathrm{d}$-axis.

Equation (3) represents PMSM motion equation:

$$
J \frac{d_{\omega m}}{d_{t}}=T_{e}-T_{L}-B \omega_{m}
$$

where $\mathrm{T}_{\mathrm{L}}$ is the load torque, $\mathrm{B}$ is the damping coefficient and $\mathrm{J}$ is moment of inertia.

We have assumed that $i_{d}=0$, so that it is possible to obtain better control results which is represented in (4)

$$
\left\{\begin{array}{c}
u_{d}=-p_{n} \omega_{m} L_{s} i_{q} \\
u_{q}=R i_{q}+L_{s} \frac{d i_{q}}{d_{t}}+p_{n} \omega_{m} \varphi_{f}
\end{array}\right.
$$

Further, the motion equation and the electromagnetic torque equation are represented in equations (5) and (6). 


$$
\begin{aligned}
T_{e} & =\frac{3}{2} p_{n} i_{q} \varphi_{f}(6) \\
J \frac{d \omega_{m}}{d_{t}} & =T_{e}-T_{L}-B \omega_{m}
\end{aligned}
$$

\section{Proposed Methodology 3.1 Fuzzy PI Controller}

The major reason for using fuzzy logic is because of its easy to use features where it doesn't require precise mathematical model of the objects. Hence it is used widely, depending on experience and expert knowledge. Fuzzy logic inference, fuzzy rule and fuzzy set theory form the basis of fuzzy control in the vehicle. In general, fuzzy control will involve reasoning machine, knowledge base and fuzzy interface. A typical fuzzy control is represented in Fig.1.

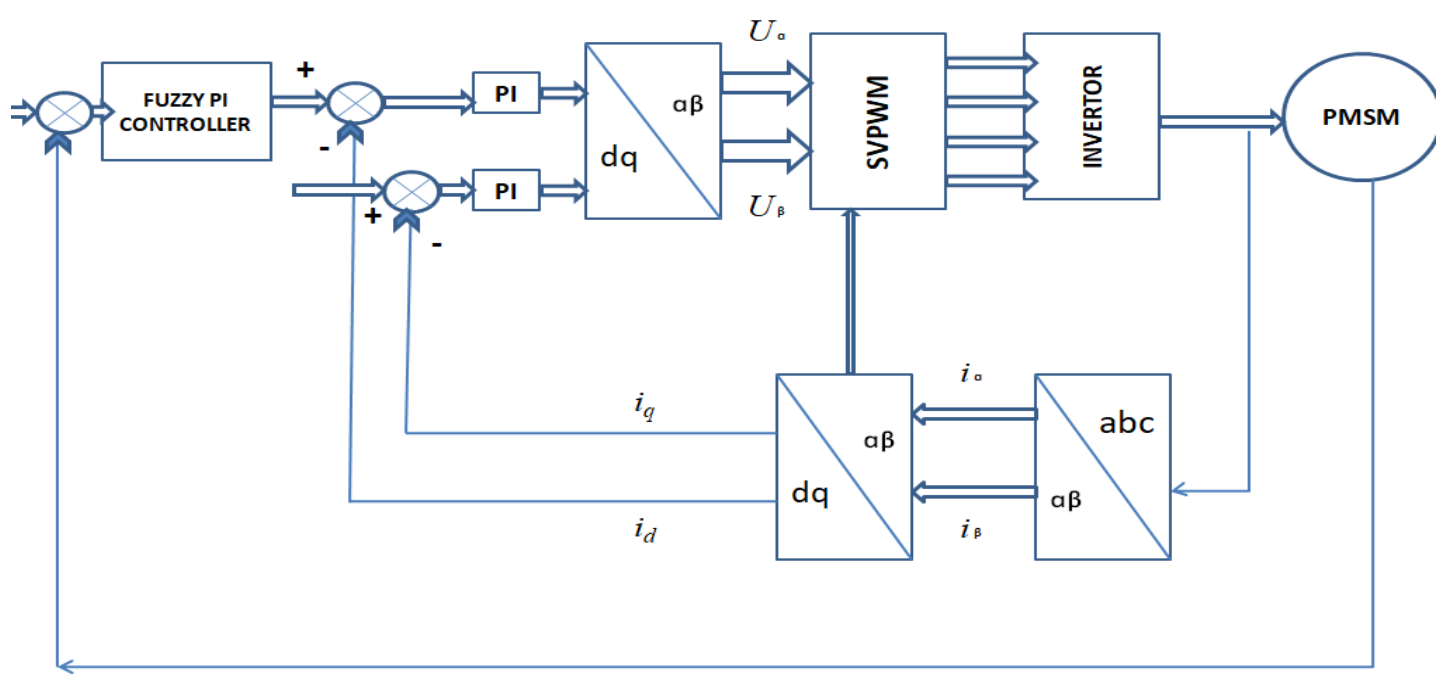

Fig.1. Fuzzy Control of Electric Vehicle using Fuzzy PI Controller

The input parameters are fed into the fuzzy interface which is used to change it into appropriate fuzzy linguistic variable. These variables are calculated using the error rate, error as well as membership function. The control algorithm of the fuzzy logic is built on 'if' and 'then' and it is used in the process of actual control [8]. The input fed into to controller is processed using the fuzzy decision module and based on its decision, the output of the logic function is obtained. Moreover, the fuzzy values generated are transformed into decisions that form a crucial part of the control system. A double-closed loop control is adopted by PMSM so that anti-disturbance is enhanced and the speed pusation is restricted. Fuzzy PI control is used by speed loop and PI control is incorporated by current loop. Speed error and rate of speed error are the input variables considered which are further mapped by $K_{1}$ and $K_{2}$ which are the quantification factors to $\mathrm{E}$ and $\mathrm{E}_{\mathrm{c}}$. There are 7 linguistic variables that are used to determine the output and input variables of fuzzy subset. The Gaussian membership function, trapezoid membership 
function, triangular membership function, etc. are some of the membership functions adopted. The triangular membership function is one of the most commonly used functions because of it quick realisation, performance control and ease of classification. Hence this membership function has been adopted in our proposed work. In order to find the rules of fuzzy control, it is necessary to choose the control variable such that the response speed of the system quickens, preventing saturation [9]. Similarly, the overshoot should be reduced by the control variable when the control system deviation is standard. On the other hand, when there is small deviation, the control variable chosen should be large and capable of restricting steady-state error within normalcy.

\subsection{Sliding Mode Controller}

One control strategy that focuses on the variable structure is the sliding mode control. A sliding mode controller outline is represented in Fig.2. It has quick response rate and is not dependent on the changes in system parameter. The following equation represents the state variable of PMSM.

$$
\left\{\begin{array}{c}
y_{1}=\omega_{r}-\omega_{m} \\
y_{2}=y_{1}=-\omega_{m}
\end{array}\right.
$$

The sliding mode surface function can be represented by the following expression:

$$
s=c x_{1}+x_{2}
$$

The expression of controller can be determined based on exponential approach law:

$$
u=\frac{1}{D}\left[c x_{2}+\varepsilon \operatorname{sgn}(s)+q s\right]
$$

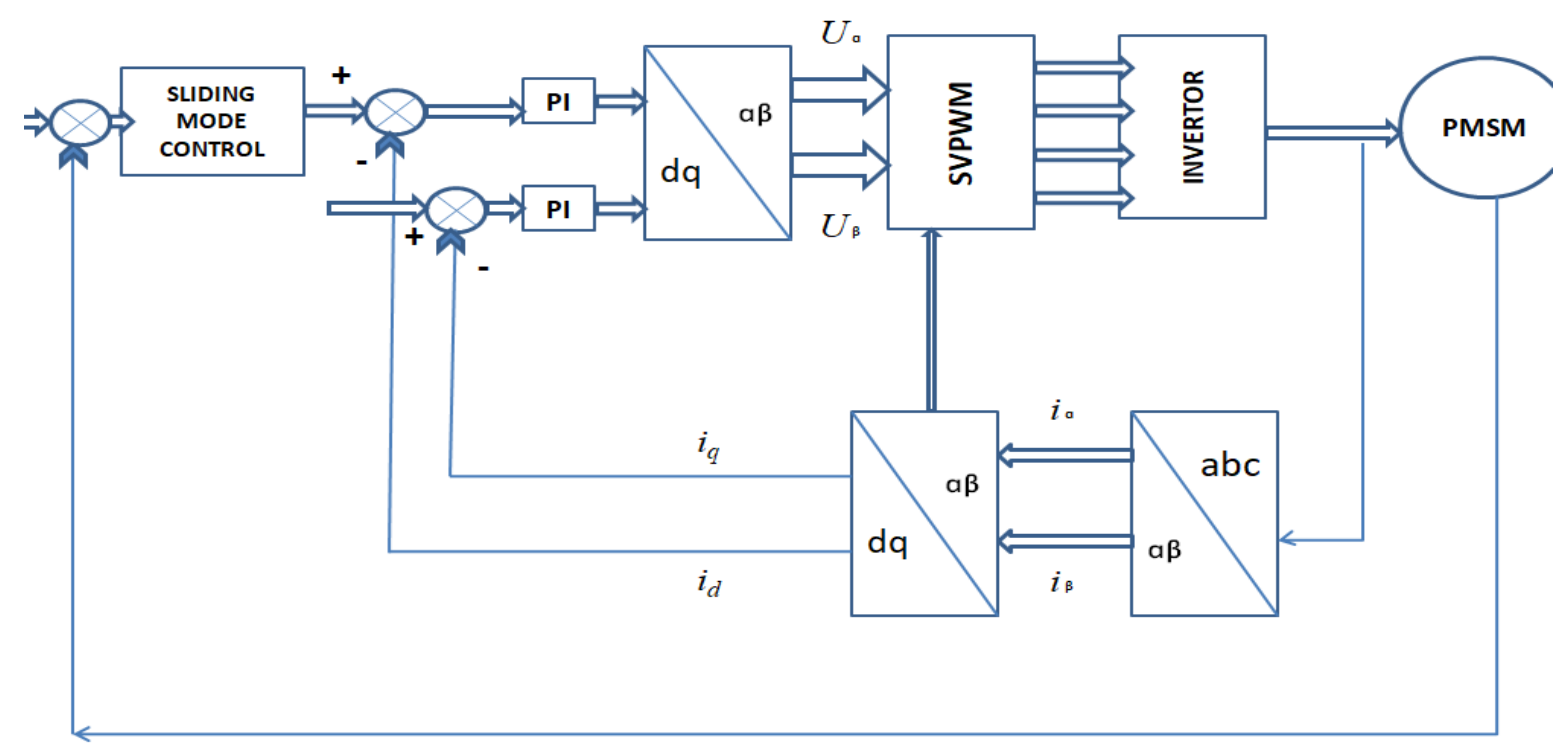

Fig.2. Sliding Mode Control 
Journal of Electrical Engineering and Automation (EEA) (2020)

Vol.02/ No. 02

Pages: 68-75

https://www.irojournals.com/iroeea

DOI: https://doi.org/10.36548/jeea.2020.2.002

\section{Result and Discussion}

The following simulation conditions are predefined by us before simulating: adopted variable step size- $25 \mathrm{tb}$, simulation time $\mathrm{Ts}=0.6$ seconds. Added torque is $10 \mathrm{Nm}$ at simulation time $\mathrm{Ts}=0.2$ seconds. Based on these simulation conditions, the output of the fuzzy PI controller is measured and the observed outputs are further used for analysis [10]. Fig.3 represents the fuzzy PI control and SMC speed waveforms of PMSM. Based on the simulation results, one can notice that the maximum value reached is 1200 rotations per minute for fuzzy PI control. However, when an emergency load is also included, the speed of the motor drops and then begins to sustain. Similarly, for the slide motor control, the maximum value reached is 1300 rotations per minute. The graph clearly shows that fuzzy PI has lesser speed overshoot and the variation of speed after addition of emergency load is also minimal.

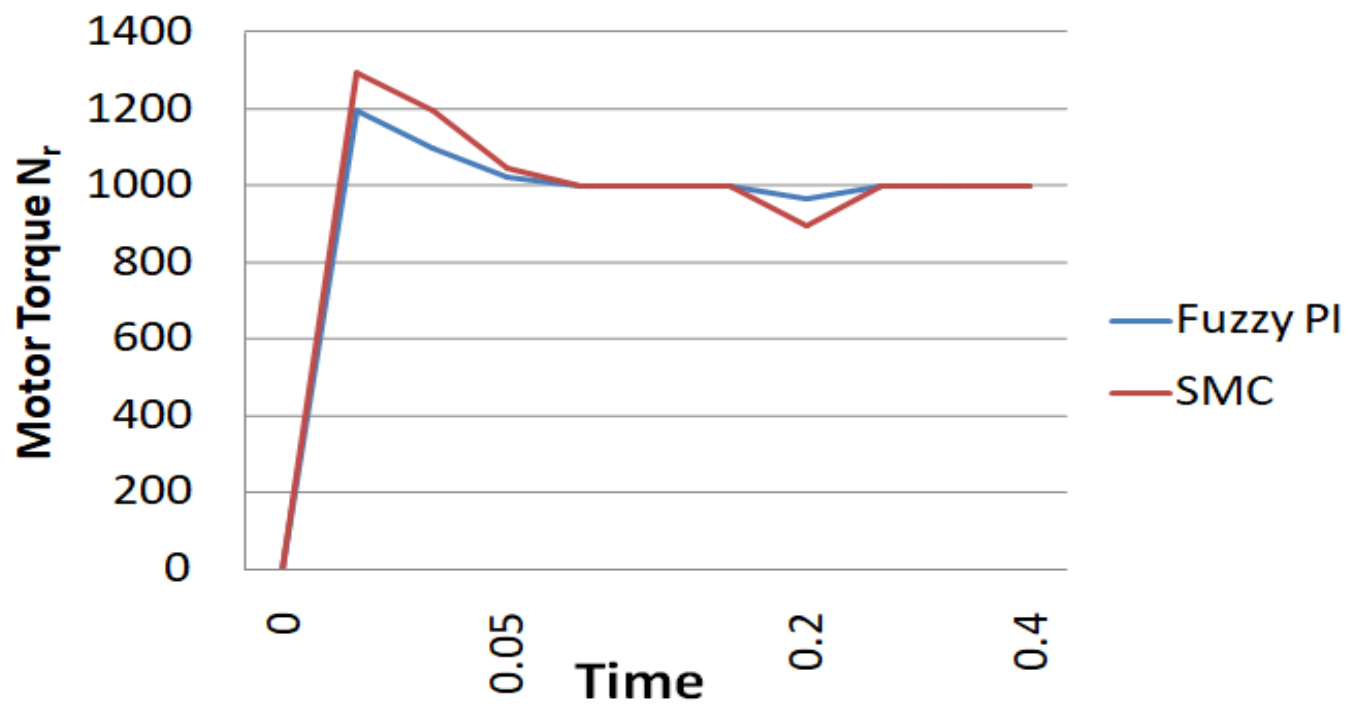

Fig.3. Speed Waveform 
Vol.02/ No. 02

Pages: 68-75

https://www.irojournals.com/iroeea

DOI: https://doi.org/10.36548/jeea.2020.2.002

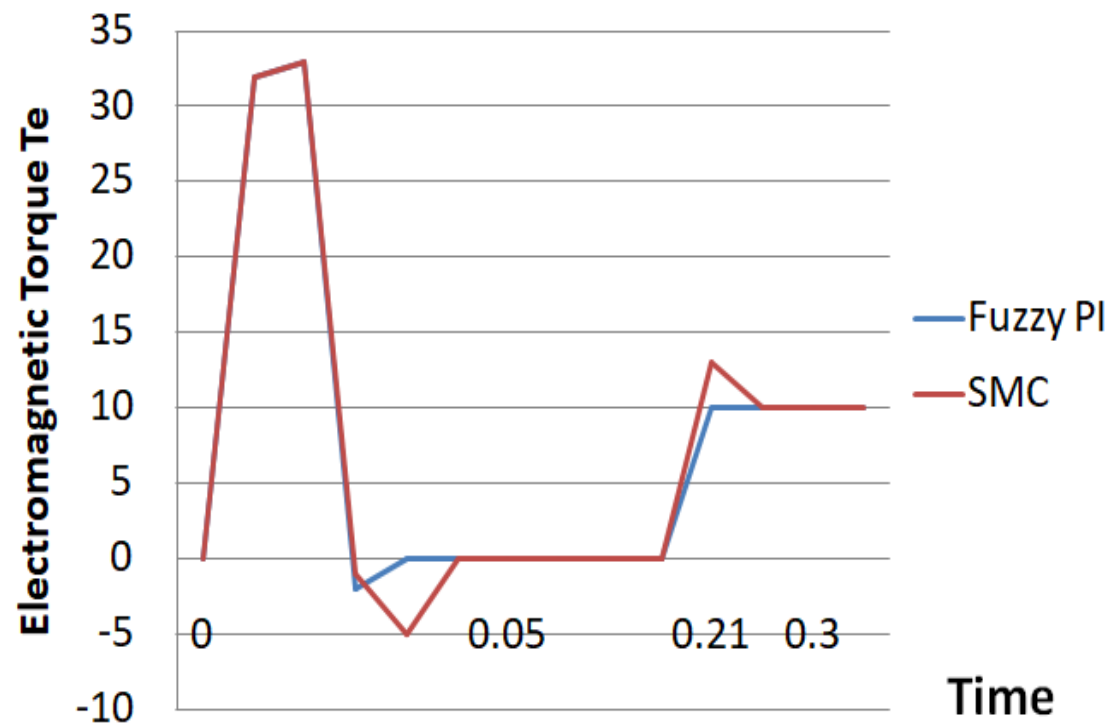

Fig.4. Torque Waveform

Fig.4 represents the torque dynamic diagram of sliding mode and fuzzy PI control. As observed in the output, in sliding mode control, the toque increases from $0 \mathrm{~N} . \mathrm{m}$ and reaches $36 \mathrm{~N} . \mathrm{m}$ and the further drops to $-2.5 \mathrm{Nm}$ before it achieves $0.07 \mathrm{~s}$ of steady state. The torques will begin to rise when emergency load is added to reach 0.23 which is the new steady state value. Similarly, for the fuzzy PI control the torque will reach $34 \mathrm{Nm}$ before droping to $-2.4 \mathrm{~N}$.m and will finally attain a steadystate value of $0.07 \mathrm{~s}$.

To evaluate the performance of the two methodologies, some parameters are taken into consideration. Table 1 represents the key parameters of PMSM along with the value of each parameter.

Table 1. Motor Parameters considered for Fuzzy PI control Simulation

\begin{tabular}{|c|c|}
\hline Motor Parameters & Value \\
\hline Load Torque, $\mathrm{T}_{\mathrm{L}}$ (N.m) & 10 \\
\hline Reference Speed $\mathrm{N}_{\text {ref }}$ (r/min) & 1000 \\
\hline
\end{tabular}


Vol.02/ No. 02

Pages: $68-75$

https://www.irojournals.com/iroeea

DOI: https://doi.org/10.36548/jeea.2020.2.002

\begin{tabular}{|c|c|}
\hline Rotation inertia J(Kg.m $\left.{ }^{2}\right)$ & 0.003 \\
\hline Magnetic linkage & 0.17 \\
\hline Stator Resistance $\mathrm{R}_{\mathrm{s}}$ & 2.87 \\
\hline & \\
\hline Stator inductance $\mathrm{L}_{\mathrm{s}}(\mathrm{mH})$ & 8.5 \\
& \\
\hline & \\
\hline
\end{tabular}

\section{Conclusion}

The proposed work establishes a fuzzy control using PMSM that uses d-q reference frame for mathematical modelling. Fuzzy control theory is the underlying principle used in the fuzzy PI speed controller. Both sliding mode control as well as fuzzy PI control are used to simulate various models of PMSM and based on the analysis of the output, it is found that the latter method plays an effective role in restraining current, torque and speed overshoot. Moreover they can also establish a good control over the parameters change due to load added during emergency. The biggest advantage of using fuzzy PI control system is that they are not dependent on parameter change or disturbance and offer better antiinterference, dynamic performance and quick response speed.

\section{References}

[1] Chen, Q., Liao, C., Ouyang, A., Li, X. and Xiao, Q. (2016) 'Research and development of inwheel motor driving technology for electric vehicles', International Journal of Electric \& Hybrid Vehicles, Vol. 8, No. 3, pp.242-253.

[2] Zheng, W. and Pi, Y. (2016) 'Study of the fractional order proportional integral controller for the permanent magnet synchronous motor based on the differential evolution algorithm', Isa Transactions, Vol. 63, No. 4, pp.387-393.

[3] Ji, H. and Li, Z. (2016) 'Research and simulation of SVPWM algorithm based on BP neural network', Key Engineering Materials, Vol. 693, No. 9, pp.1391-1396.

[4] Xu, X. and Lin, H. (2014) 'Integrated design for permanent magnet synchronous motor servo systems based on dynamic sliding mode control', Transactions of China Electrotechnical Society, Vol. 29, No. 5, pp.77-83. 
[5] Zhu, W., Fu, D. and Ge, D. (2016) 'PMSM control system based on RBF neural network'. Electronic Science and Technology, Vol. 29, No. 1, pp.161-164, 168.

[6] Yuan, C. and Lin, W. (2009) 'Fuzzy sliding mode control based on genetic algorithm for brushless DC motor', Small \& Special Electrical Machines, Vol. 37, No. 2, pp.43-46.

[7] Opresnik, D., Fiasché, M., Taisch, M. and Hirsch, M. (2017) 'An evolving fuzzy inference system for extraction of rule set for planning a product-service strategy', Information Technology \& Management, Vol. 18, No. 2, pp.131-147.

[8] Zhang, J., Ming, L., Shen, T., Liu, L. and Bo, L. (2017) 'Sliding mode control for a class of nonlinear multi-agent system with time-delay and uncertainties'. IEEE Transactions on Industrial Electronics, Vol. 65, No. 1, pp.1-1.

[9] Zhang, P., Jia, H., Wang, Y. and Liu, Y. (2016) 'Implementation of fuzzy-PI vector control system of BLDCM', Mechanical \& Electrical Engineering Magazine, Vol. 33, No. 2, pp.202-206.

[10] W. Sun, Z. Yang, X. Zhang, and Y. Liu, "Energy-efficient neighbour discovery in mobile ad hoc and wireless sensor networks: A survey," IEEE Commun. Surveys Tuts., vol. 16, no. 3, pp. 1448-1459, 3rd Quart., 2014.

[11] Yi, J., Yi, S. and Huang, Q. (2016) 'Active-disturbance rejection controller for permanent magnet motor drive system control based on load observer', Transactions of China Electrotechnical Society, Vol. 31, No. 18, pp.29-36.

[12] Verbenko, I. and Tkachenko, R. (2015) 'Gantry and bridge cranes neuro-fuzzy control by using neural-like structures of geometric transformations', Wydawnictwo Politechniki Krakowskiej Im Tadeusza Kościuszki, pp.53-68.

[13] Li, M. (2017) 'IMC of variable-frequency speed control system of permanent magnet synchronous motors', Electrical Automation, Vol. 39, No. 4, pp.11-14.

Biography: Dr. Prof. Subarna Shakya is currently a Professor of Computer Engineering, Department of Electronics and Computer Engineering, Central Campus, Institute of Engineering, Pulchowk, Tribhuvan University, Coordinator (IOE), LEADER Project (Links in Europe and Asia for engineering, education, Enterprise and Research exchanges), ERASMUS MUNDUS. She received MSc and $\mathrm{PhD}$ degrees in Computer Engineering from the Lviv Polytechnic National University, Ukraine, 1996 and 2000 respectively. Her research area includes E-Government system, Computer Systems \& Simulation, Distributed \& Cloud computing, Software Engineering \& Information System, Computer Architecture, Information Security for E-Government, Multimedia system 